\title{
The work environment quality at the shaft furnace of a crude lead tapping and refining process
}

\author{
K. Lach ${ }^{1}, \mathrm{~K}$. Klouda ${ }^{2}$ \& S. Brádka ${ }^{3}$ \\ ${ }^{1}$ Public Health Institute, Ostrava, Czech Republic \\ ${ }^{2}$ State Office for Nuclear Safety, Prague, Czech Republic \\ ${ }^{3}$ National Institute for Nuclear, Chemical and \\ Biological Protection, Czech Republic
}

\begin{abstract}
The paper deals with the state of workplaces which process spent batteries and accumulators by melting them in a shaft furnace, with subsequent refining of crude lead. The first part of this study deals with the working environment near the blast furnace processing crude lead. The second part deals with the incidence and composition of particulate matter in the environment refining crude lead.

Lead waste is melted mostly from discarded (broken) lead starter accumulators. Burning of coke inside a shaft furnace causes the melting of lead and its reduction. Measurements of distribution of nano- and microparticles were performed during the described operations. The particles were collected by means of a Nano-ID ${ }^{\mathbb{B}}$ Select fractional sampler to analyze their morphology and chemical compositions. Spherical, cubic, cuboidal, cylindrical and amorphous particles were found, with the prevailing composition of $\mathrm{Pb}$ and $\mathrm{PbS}$ alloys. However, the atmosphere in proximity to the furnace also contains particles of other heavy metals that pose a high health risk.

The crude lead refining process eliminates metallic impurities $(\mathrm{Cu}, \mathrm{Zn}, \mathrm{Ag}, \mathrm{Au}$, $\mathrm{Sn}, \mathrm{As}, \mathrm{Sb}$ ) from lead obtaining pure lead and other metals that can be further reused. Measurement of the size dependent distribution of fine aerosol, chemical composition and morphology of nano- and microparticles and the surface area equivalent dose of particles in the size range of 10 to 1000 nanometers were carried out near the copper removing process.

Keywords: air pollution, heavy metals, dust composition, working environment, metals mass distribution.
\end{abstract}




\section{Introduction}

Lead is a metal that has been known for a very long time. It has been well known mainly because the deposits are quite widespread. The Egyptians considered lead to be the forefather of all metals. The Ancient Romans knew that lead, so widely used, might cause health problems. Lead poisoning was a disease of the rich - who were exposed to it most of all: water piping, dishes, and utensils, wine goblets, even leadbased make-up. The use of lead has gradually changed. In history it was pigments, ammunition, and piping, but nowadays mainly batteries are produced from lead. If lead is properly handled, there is no need to be afraid of the negative effects now. The smelting works in Príbram has been a part of the history of the town for more than two hundred years. Mining and smelting - they both belong to Príbram and are mentioned in many historical, geographical and metallurgical books. It was deep in the past when the tradition of lead and silver production began in the region of Príbram. For the whole history from end of 13th century until the end of the year 2005 has the work produced on the whole 1,377 thousand tons of lead and 5,160 tons of silver.

Metallurgical methods for extraction of metals from lead ores have been abandoned. The raw materials now include mostly spent car batteries and other secondary raw materials (recycled scrap metal).

The inhalation of aerosol particles is known to be a significant pathway for heavy metals to reach the internal organs of the body. Lead aerosols undoubtedly represents a considerable risk factor in many industries and environments [1-4], especially if thermally strained, e.g. melted or strained mechanically when e.g. brushed or simply cut. Ugu et al. [5] deals with a very similar study focusing on air quality at workplaces. In this paper occurrence and morphological properties of $\mathrm{Pb}$-rich particles are evaluated. Schreck et al. [6] investigated the environmental effects of process particles from a lead-recycling facility after atmospheric deposition on soils and potential run-off to surface waters. The influence of ageing and soil properties on metal transfer and ecotoxicity was studied using three different soils and comparing various aged, spiked or historically long-term polluted soils.

Despite the fact that all employees wear all-face masks with filters to clean the air they breathe in, this working environment represents an extremely interesting object for investigation. The management of the company Kovohutě Prríbram nástupnická, a.s. was very accommodating and the measurements were conducted under conditions of full operation. The lead production technology consists of two independent operations. The first part produces crude lead by reduction melting in a shaft furnace. The produced lead ingots contain some accompanying metals, mainly zinc, copper, tin, antimony and silver and they represent the feedstock for the second - refining - stage of the metallurgical process.

Accumulator waste accounts for over $40 \%$ of the total lead waste. Spent accumulators represent mixed waste containing plastic, hard lead, lead oxides and sulfates and residual sulfuric acid. Partly sorted accumulator waste, including other waste products containing lead, makes up most of the charge in the shaft furnace. Other components of the charge include recycled slag, limestone and oxidized iron filings. 
Burning of coke in the shaft furnace causes melting of lead and its reduction. The slag formed on its surface is poured into special vessels (the so-called ingot molds) and left to cool down. Subsequently, a part of the produced slag is separated and returned back to the furnace. The main reason is to improve the slag-forming properties of the melt, particularly the melting point and viscosity. The slag tapping is performed every 15-20 minutes. Melted lead, which is concentrated at the bottom part of the shaft furnace, pours out from the furnace after the tapping through a siphon tap into ingot moulds to cool down and to form ingots weighing ca. $1500 \mathrm{~kg}$.

Crude lead contains substantial quantities of various impurities and therefore it is further refined in several stages to remove copper (reaction with sulfur), Sn, As, Sb (oxidation), precious metals Ag (addition of $\mathrm{Zn}$ - Parkes process, i.e. formation of a $\mathrm{Zn}-\mathrm{Ag}$ alloy which solidifies on the lead surface) and subsequently $\mathrm{Zn}$ is removed by vacuum distillation.

Lead refining is a discontinuous process based on different physicochemical properties of the metal admixtures. Individual refining procedures are performed in separate boilers. Crude lead ingots are melted and mechanical impurities are removed which rise to the surface of the lead bath due to their different specific weights and they are removed as the so-called dross.

To remove $\mathrm{Cu}$ the process uses limited solubility of $\mathrm{Cu}$ in lead at low temperatures $\left(350^{\circ} \mathrm{C}\right)$ and its higher affinity to sulfur. Sulfur (pyrites) reacts with copper to form black $\mathrm{Cu}_{2} \mathrm{~S}$ which rises to the melt surface and it is removed from there. Four separate steps are used to remove silver, gold, tin, antimony and zinc from lead. The refining process always takes into account customers' requirements and some of the refining steps may be skipped.

\section{Measurement and sampling}

The objective of the study was to determine current conditions in the working environment and to focus on distribution of dust particles in terms of their size, morphology and chemical composition.

As the technology of pure lead production is divided into two separate sections, the sampling and measurements were also divided into two parts. First, measurements in the proximity of the shaft furnace hearth were performed, and second, samples were collected in the course of the lead refining process, specifically in the proximity of the copper removal process.

\subsection{Instruments used}

A Fast Mobility Particle Sizer (FMPS, Model 3091, TSI Inc., St. Paul, MN) (Knutson and Whitby, 1975) was used for particle size distribution and total number concentration measurements. Size distributions were measured from 5.6 to $560 \mathrm{~nm}$. Size dependent sampling was carried out by means of a wide-range aerosol sampling system - Nano-ID ${ }^{\circledR}$ Select, (Naneum Ltd., UK). The samples of all 12 stages collected by the Nano-ID ${ }^{\circledR}$ Select were analysed for metal content by ICP-MS, THERMO XSeriesII. Prior to analysis, samples were mineralized using a microwave system (Milestone MLS 1200 Mega, Milestone Inc., CT). Standard 
analytical procedure for samples of dust collected from the air on polymer or quartz filters and membranes were used. Digestion was carried out in closed vessels preventing loss of volatile elements like As or $\mathrm{Sb}$. The glass slides from the impactor and the polymer membranes (nets) from the diffusion cell of the Nano-ID ${ }^{\circledR}$ Select sampler were placed into the vessels of the microwave oven along with $5 \mathrm{ml}$ of concentrated nitric acid and $1 \mathrm{ml}$ hydrogen peroxide. The temperature of digestion is $180^{\circ} \mathrm{C}$ and is automatically controlled using a computer interface. The time of digestion at this temperature is 10 minutes. Once the digestion is complete, the samples are allowed to cool and then samples are diluted with high-purity water up to a volume of $50 \mathrm{ml}$. Finally samples were analysed with ICP-MS. To quantify the background contamination on the glasses and nylon nets, a blank glass slide and a blank nylon net were also analysed by ICP-MS during each sampling event.

Furthermore, in addition to the bulk chemical composition it is also very important to know the size, shape and composition of individual particles collected from the air, i.e. their morphology. This information is particularly important for further consideration in relation to the toxicity of individual fractions of airborne dust. The Nano-ID ${ }^{\circledR}$ Select sampler was used to collect particulate matter for observations on SEM only in the range from $250 \mathrm{~nm}$ to $30 \mu \mathrm{m}$. The impactor collects airborne particles between $250 \mathrm{~nm}$ and $30 \mu \mathrm{m}$ on glass slides, which are useable as substrates for chemical analysis but not directly for SEM. Hence, for SEM imaging it was decided to use a carbon sticker on the glass slides in the range from $1 \mu \mathrm{m}$ to $30 \mu \mathrm{m}$. The high speed air flow through the sampler impactor nozzle slot causes the penetration of solid particles present into the mass of the carbon sticker, which together with surface roughness affects their identification and quality of observations. For these reasons, in the case of the 6th and 7 th stages $(0.25 \mu \mathrm{m}-1.0 \mu \mathrm{m})$ of the sampler, TEM grid collection substrates were used instead.

Determination of the number and distribution of fine to ultrafine aerosol particles at the shaft furnace was performed with SMPS (Scanning Mobility Particle Sizer) 3934.

A scanning electron microscope (SEM) (FEI QUANTA 450 FEG, FEI Company, WA) equipped with BSE (backscattered electrons), LFD (large-field detector) and ETD (secondary electrons) detectors was used for observing the morphology of particles. The SEM was used to image and analyze surface topography, collect backscattered electron images and characterize and determine elemental composition of particles using an SDD EDX (silicon drift detector for energy-dispersive X-ray spectroscopy). For observing electrically non-conductive particles, a low vacuum $(50 \mathrm{~Pa})$ was primarily used for better resolution and contrast.

AeroTrak $^{\circledR}$ Nanoparticle Aerosol Monitor 9000 (TSI Inc., St. Paul, MN) was used for determination of the surface area of nanoparticle aerosols that deposit in the lung, corresponding to the ICRP model lung deposition curves (Human Respiratory Tract Model for Radiological Protection) for the tracheobronchial (TB) and alveolar (A) regions of the human respiratory tract. 


\subsection{Results and discussion}

\subsection{Environment near the crude lead tapping}

The measuring and sampling apparatus was situated ca. $4 \mathrm{~m}$ from the lead tapping point of the shaft furnace. Already the first pilot measurement with FMPS indicated an excessive concentration of fine dust particles which was so high that after ca. 30 seconds the device was choked and contaminated. Later, the spectrometer had to be professionally decontaminated. For this reason we decided not to use Aerotrak 9000 to determine the surface area of the particles deposited in lungs. We only collected samples with the Nano- ID $^{\circledR}$ Select sampler.

\subsubsection{Chemical analysis}

All collected fractions ranging from $1 \mathrm{~nm}$ to $30 \mu \mathrm{m}$ were analyzed for their chemical composition. The results confirmed high concentrations of lead. Other elements found, interesting from the viewpoint of working environment contamination, included $\mathrm{Cd}, \mathrm{As}, \mathrm{Cu}$ and $\mathrm{Zn}$. Their overall concentrations recorded in the course of the measurements are provided in Table 1. Examples of the weight distribution are provided for lead and tin in Figs 1 and 2. Similarly to most of the other monitored metals, the majority of the mass was represented by particles ranging from $250 \mathrm{~nm}$ to $1000 \mathrm{~nm}$. From the toxicological point of view, this size represents a very problematic fraction which penetrates and deposits in tracheobronchial and alveolar parts of the respiratory tract.

Table 1: Total concentration of metals of interest in front of discharge taphole of the shaft furnace.

\begin{tabular}{lccccccc}
\hline Element & $\mathbf{P b}$ & $\mathbf{A s}$ & $\mathbf{C d}$ & $\mathbf{Z n}$ & $\mathbf{C u}$ & $\mathbf{S n}$ & $\mathbf{S b}$ \\
\hline $\begin{array}{l}\text { Total concentration } \\
{\left[\boldsymbol{\mu g} / \mathbf{m}^{3}\right]}\end{array}$ & 39.6 & 0.90 & 0.28 & 3.17 & 0.90 & 0.96 & 0.37 \\
\hline
\end{tabular}

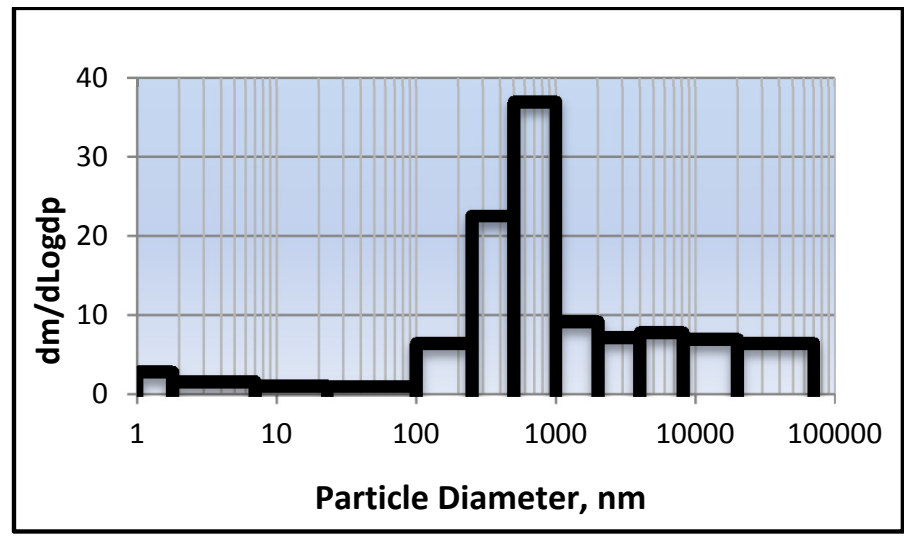

Figure 1: Lead - size dependent distribution, $\mu \mathrm{g} / \mathrm{m}^{3}$, measured in front of the taphole. 


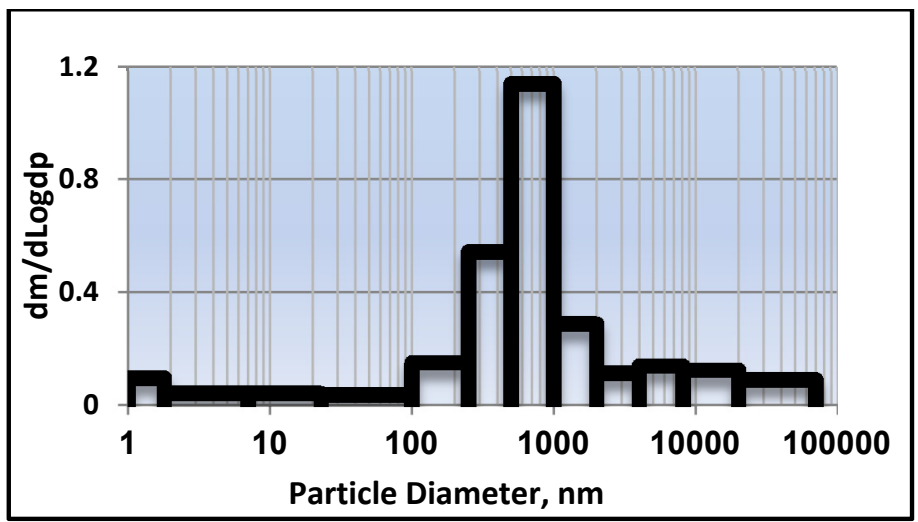

Figure 2: Tin - size dependent distribution, $\mu \mathrm{g} / \mathrm{m}^{3}$, measured in front of the taphole.

\subsubsection{Electron microscopy observations}

All seven sampling positions from the impactor of the Nano-ID ${ }^{\circledR}$ Select sampler were gradually evaluated with an electron microscope. Morphology of the present particles consists of crystalline formations, spherical particles and irregular thin sheets structures. The space in front of the furnace is connected to the outdoor environment and, despite that, there was a distinct sulfuric odor reminiscent of sulfur dioxide. The emissions of sulfur-containing compounds are formed by the reaction of residual sulfuric acid with the furnace charge and lead. This has been very clearly confirmed by the EDX elemental analysis. The absolute majority of the present particles, from several tens of nanometers to a few microns, were solid solutions of lead sulfide and lead - Fig. 3(a), (b). The elemental analysis also indicated that the molar ratio $\mathrm{Pb}: \mathrm{S}$ is $>1$. Lead sulfide and lead are mutually miscible without limitation [7]. A relatively pure lead sulfide occurs in the form of cubic crystals and prisms. There are also carbon particles, probably fine coke and carbon black, and also some octahedral crystals of magnetite were observed. Zinc oxide crystals are less frequent and they are in the form of rollers, often with a conic end - Fig. 3(c). Occurrence of PbS nanoparticles has been also confirmed - Fig. 3(d).

\subsubsection{Concentration and size dependent distribution}

Contamination of the environment with dust particles in a relatively small space at the shaft furnace taphole reached very high values and on average exceeded the concentration of $10^{8} / \mathrm{cm}^{3}$. For this reason the application of FMPS was not successful. The resulting distribution measured with SMPS is shown in Fig. 4. The diagram represents an average of four measurements performed at the time of lead tapping when the air pollution from airborne dust is at its maximum. The diagram shows a sharp increase of concentration of nanoparticles smaller than $15 \mathrm{~nm}$. Another maximum is ca. at $30 \mathrm{~nm}$. 


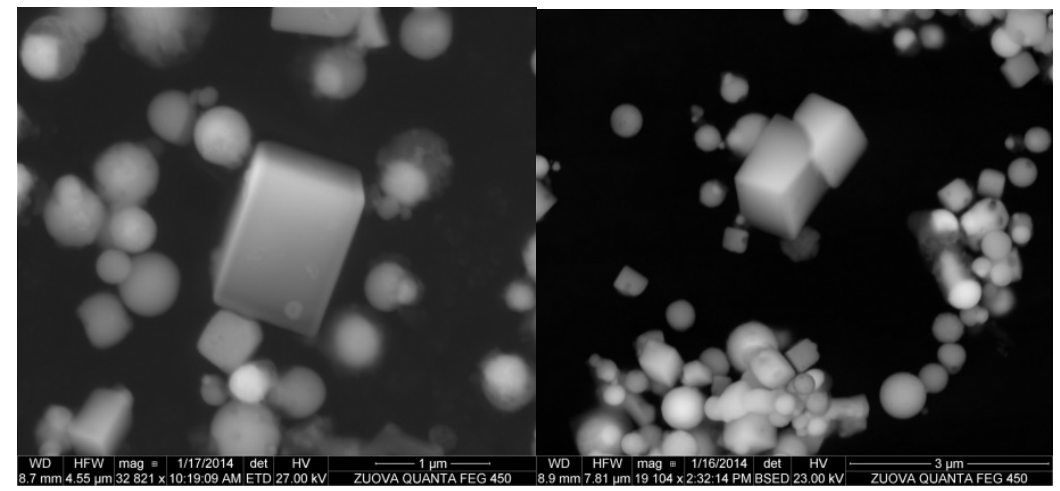

(a)

(b)

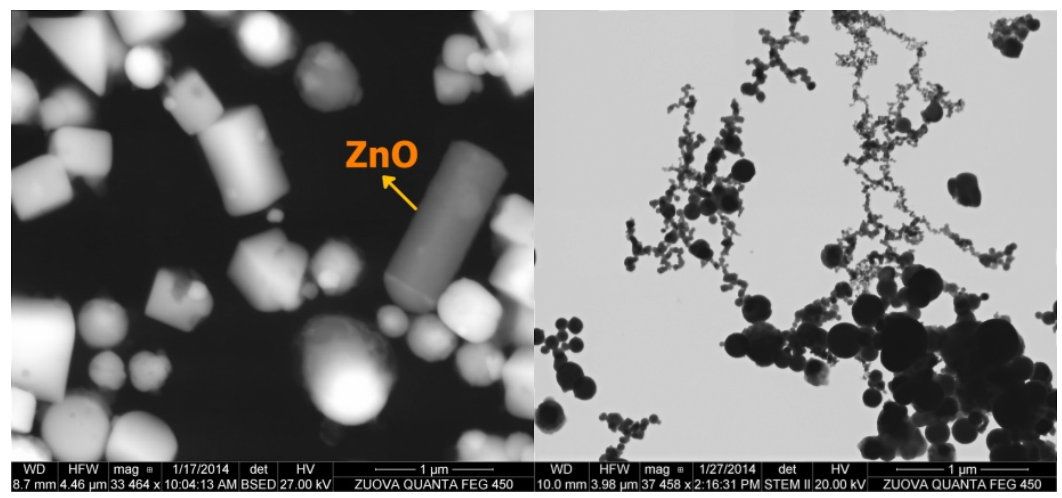

(c)

(d)

Figure 3: $\quad$ SEM images of particles captured in front of a taphole of the shaft furnace. (a) and (b) morphology of crystals of PbS; (c) cylindrical crystal of zinc oxide; (d) nano-spheres of $\mathrm{PbS}$.

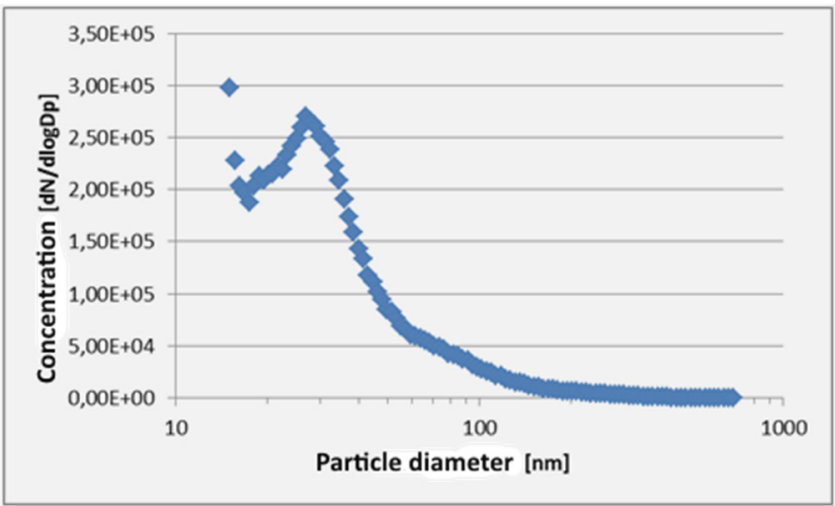

Figure 4: Average of four measurements of the particle size distribution during the process of crude lead tapping. 


\subsection{Environment at the lead refining process}

The discontinuous process of crude lead refining is performed in four stages in kettles heated with gas. Each kettle is used for a specific stage of the refining process. The first stage of the process, on which the study is focused, removes copper from lead by adding iron disulfide (pyrite). The process exploits the limited solubility of copper in lead at lower temperatures $\left(350^{\circ} \mathrm{C}\right)$ and the higher affinity of copper to sulfur. Sulfur from the pyrite reacts with copper to form black $\mathrm{Cu}_{2} \mathrm{~S}$ which rises to the surface of the melt and it is removed from there. The addition of pyrite on the melt surface is accompanied by intense stirring of the melt.

\subsubsection{Chemical analysis}

All the refining stages are performed concurrently in a big hall. The generated emissions are extracted by intense ventilation and the forcing of fresh air from outside into the hall. Chemical analysis was performed, as in the previous case, for all size fractions obtained from the impactor of the Nano-ID ${ }^{\circledR}$ Select sampler. The results have shown that the lead emissions consisted mostly of significantly bigger particles than in the emissions at the shaft furnace, i.e. the maximum of the distribution curve was shifted to higher values (Fig. 5). Similar changes in distribution were found also for the other metals - see cadmium as the example in Fig. 6. In general, the contamination with metals was significantly lower for most metals except arsenic and antimony and the measured concentrations of the individual metals are provided in Table 2.

Table 2: Total concentration of metals of interest near the process of copper removal.

\begin{tabular}{lccccccc}
\hline Element & $\mathbf{P b}$ & $\mathbf{A s}$ & $\mathbf{C d}$ & $\mathbf{Z n}$ & $\mathbf{C u}$ & $\mathbf{S n}$ & $\mathbf{S b}$ \\
\hline $\begin{array}{l}\text { Total concentration } \\
{\left[\boldsymbol{\mu g} / \mathbf{m}^{3}\right]}\end{array}$ & 32.1 & 4.2 & 0.08 & 2.9 & 0.73 & 0.56 & 2.29 \\
\hline
\end{tabular}

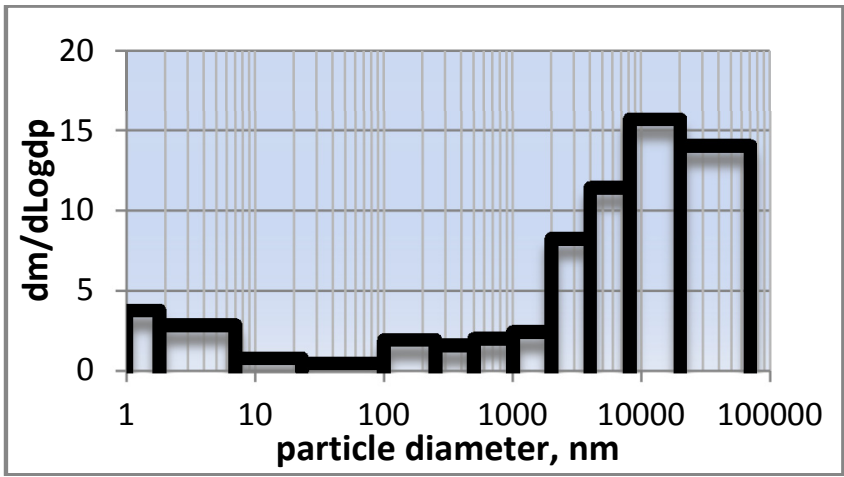

Figure 5: Lead size-dependent distribution $\left[\mu \mathrm{g} / \mathrm{m}^{3}\right]$, measured near the process of copper removal. 


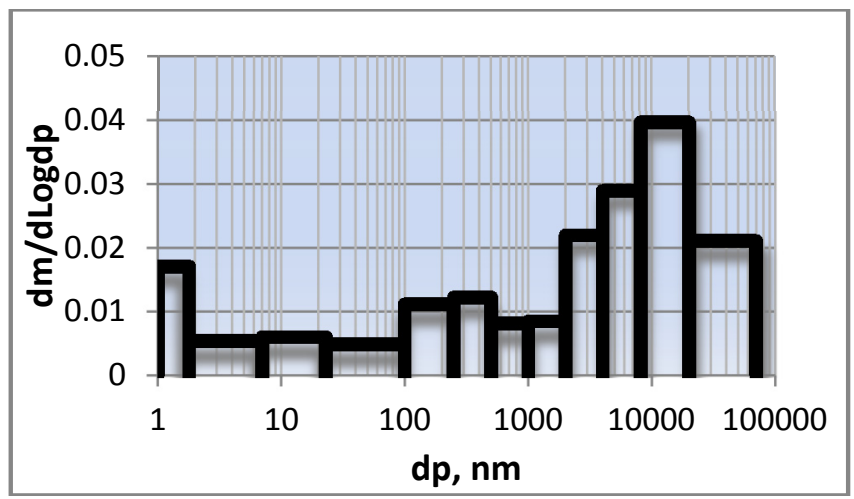

Figure 6: Cadmium - size dependent distribution $\left[\mu \mathrm{g} / \mathrm{m}^{3}\right]$, measured near the process of copper removal.

\subsubsection{Electron microscopy observations}

Results obtained with electron microscopy confirmed a high diversity in the morphology and species of metals present of metals present. Most of the observed particles were agglomerates of different sizes made up of primary particles smaller than $1 \mu \mathrm{m}$. The primary particles were metals in pure form. Particles of $\mathrm{PbS}$ were very rare. Fig. 7(a), (b) show examples of such clusters. The prevailing elements are zinc, copper, tin and lead, as well as arsenic. In terms of the character and morphology, the particles were mostly formed by sublimation and condensation of metal vapors.

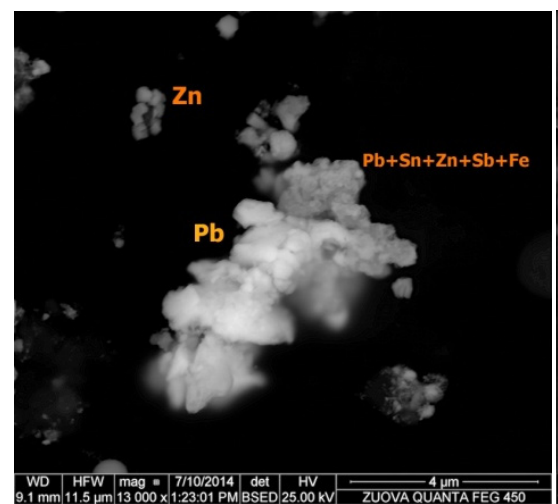

(a)

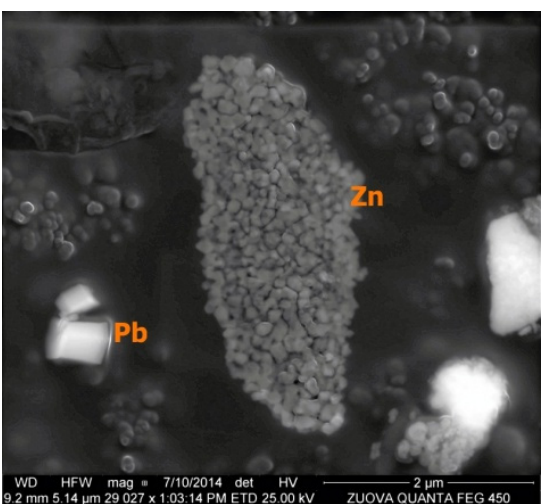

(b)

Figure 7: SEM observation of particles captured in the lead refining environment, (a) cluster composed of different primary particles, (b) cluster composed of a large number of primary zinc particles. 


\subsubsection{Concentration and size dependent distribution}

Distribution and overall concentration of submicron particles strongly depends on the momentary status of the copper removing process. The highest development of particles smaller than $100 \mathrm{~nm}$ occurs as a result of pyrite addition. Pyrite is added on the surface of melted lead and vigorously stirred. The above-described facts and the intense chemical reaction result in a large quantity of nanoparticles released in a short period of time. The change in the distribution and the intense development of nanoparticles are visible in Fig. 8. Before emission of nanoparticles the composition of the atmosphere was fairly stable and the prevailing size of nanoparticles was ca. $50 \mathrm{~nm}$; particles sized ca. $10 \mathrm{~nm}$ appeared immediately after the beginning of the chemical reaction between copper and pyrite and emission of the bigger particles subsided.

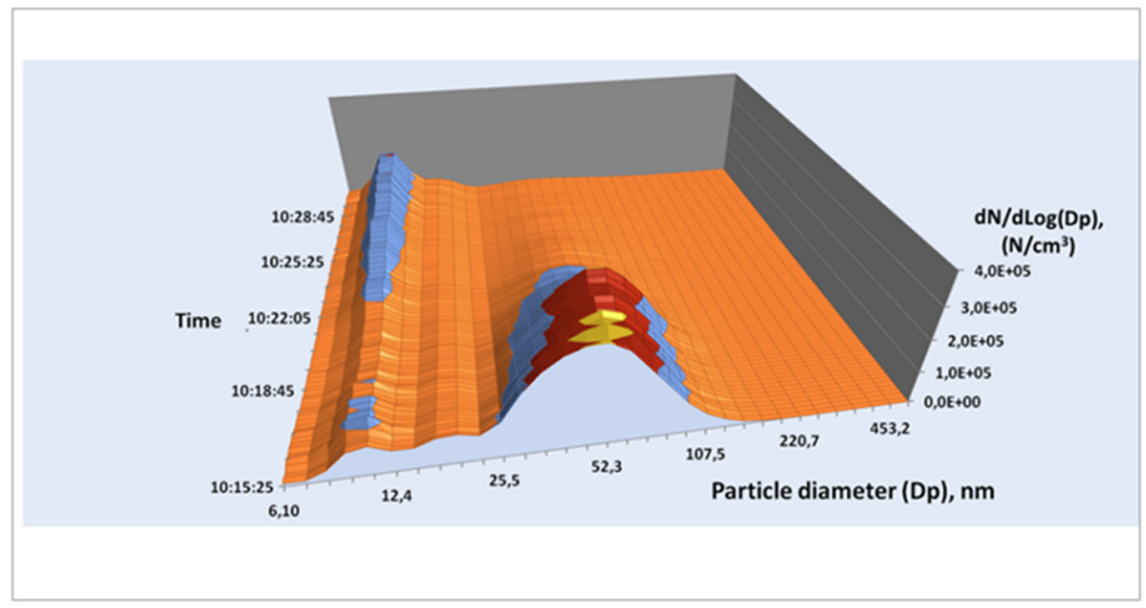

Figure 8: 3-D plot showing changes in the distribution of nanoparticles after the addition of pyrite.

\section{Conclusion}

The study measured working environment parameters in the proximity of the hearth of the shaft furnace processing lead waste. The measurement was performed ca. 3 meters from the tapping point of the furnace. The environment was strongly contaminated with crystals and fine spherical particles of lead sulfide. The overall concentration of particles smaller than $500 \mathrm{~nm}$ at the time of casting of crude lead into ingot molds exceeded $10^{8} / \mathrm{cm}^{3}$.

The environmental parameters were different during the refining process of crude lead. Particles in the atmosphere were mostly metals and they readily created fairly big, stable and mostly heterogeneous aggregates.

The examined environment was strongly contaminated with heavy metals. Due to the demonstrated presence of heavy metals in the atmosphere, both during crude lead casting and during its refinement, the workers observe very strict hygienic 
and working restrictions. Probably the most important of them are state-of-the-art overpressure respiratory helmets with Airstream AH4 air filter for forced filtration. A concentration of lead in the whole blood of workers is checked regularly to be less than $400 \mu \mathrm{g} / \mathrm{l}$.

\section{Acknowledgements}

Special thanks to Brian Steer from Naneum Ltd. for his careful perusal and proofreading.

The authors thank the management of Kovohutě Příbram nástupnická, a.s. for their help and very forthcoming approach during our presence in the plant.

\section{References}

[1] Burtis, C.A., Aswood, E.R. Tietz textbook of Clinical Chemistry, Third Edition. W.B. Saunders Company. ISBN 0-7216-5610-2, pp. 989-991, 1999.

[2] Donaldson K, Li XY, MacNee W. Ultrafine (nanometer) particle-mediated lung injury. J Aerosol Sci; 29, pp. 553-60, 1998.

[3] Lokitch, G., Perspectives on lead toxicity. Clin. Biochem, 26, pp. 371-381, 1993.

[4] Royce, S.E., Needleman, H.L., Eds.: Case Studies in Environmental Medicine: Lead Toxicity. U.S. Public health Service, ATSDR, 1990.

[5] Uzu G., et al. Characterization of lead-recycling facility emissions at various workplaces: Major insights for sanitary risks assessment. Journal of Hazardous Materials, 186(2-3), pp. 1018-1027, 2011.

[6] Schreck E. et al. Influence of soil ageing on bioavailability and ecotoxicity of lead carried by process waste metallic ultrafine particles. Chemosphere. 85 (10), pp. 1555-1562, 2011.

[7] Kullerud, G. The Lead-Sulfen System, American Journal of Science, 267-A., pp. 233-256, 1969. 